\title{
LA CONCEPCIÓN ERÓTICA DE LA SUBJETIVIDAD EN LA FENOMENOLOGÍA DEL ESPÍRITU. ALCANCES Y LÍMITES
}

\section{THE EROTIC CONCEPTION OF SUBJECTIVITY IN THE PHENOMENOLOGY OF SPIRIT. SCOPE AND LIMITS}

\author{
Milton ABELLÓN* \\ CONICET-INEO-CIF / UBA
}

RESUMEN: El presente trabajo estudia la concepción erótica de la subjetividad en la Fenomenología del espíritu (1807) de Hegel. Las tesis que intentamos mostrar son dos. La primera es que la concepción erótica de la subjetividad tiene un sentido muy restringido: es la referencia negativa y puramente inmediata a la cosa viva, la aniquilación del objeto natural que no alcanza la completa negación del ser-otro porque la dimensión erótica de la subjetividad requiere e implica la autonomía del objeto en cuestión. La segunda tesis es que, en cuanto posicionamiento práctico y negativo de la autoconciencia respecto de su objeto, la concepción erótica de la subjetividad no se limita al Capítulo IV, aunque es en este último, y específicamente en su parte introductoria, donde se establecen los caracteres propios de dicha concepción.

Palabras Clave: Fenomenología del espiritu, deseo (Begierde), autoconciencia erótica, goce (Genuß), trabajo (Arbeit).

\footnotetext{
* Docente de la Facultad de Filosofía y Letras de la Universidad de Buenos Aires. Dirección postal: Miñones 2073, Cuidad autónoma de Buenos Aires, Argentina. E-mail: milton.abellon@gmail.com. Este trabajo ha sido posible gracias al financiamiento del Consejo nacional de investigaciones científicas y técnicas (CONICET).
} 
AвsтRACт: The present paper studies the erotic conception of subjectivity in the Phenomenology of Spirit (1807) of Hegel. The theses that we try to prove are two. The first is that the erotic conception of subjectivity has a very restricted meaning: it is the negative and purely immediate reference to the living thing, the annihilation of the natural object that does not achieve the complete negation of the being-other because the erotic dimension of subjectivity requires and implies the autonomy of the object. The second thesis is that, as a practical and negative position of the self-consciousness with respect to its object, the erotic conception of subjectivity is not limited to Chapter IV, although it is in this chapter, and specifically in its introductory part, where the essential characters of that conception are established.

KeYwords: Phenomenology of Spirit, desire (Begierde), erotic self-consciousness, enjoyment (Genuß), work (Arbeit).

\section{Introducción}

Hegel explicita el «carácter erótico de la subjetividad» al comienzo del Capítulo IV de la Fenomenología del espiritu (1807; FE), "La verdad de la certeza de sí mismo", cuando define la autoconciencia (Selbstbewußtsein) como "deseo» (Begierde) $(F E, 104)^{1}$. El contexto general de esta caracterización es doble. Por un lado, contiene la recapitulación de los resultados de los tres primeros capítulos de la FE, donde se expone la figura de la Conciencia (Bewußtsein). Por otro lado, consta de la presentación de la figura de la Autoconciencia, expuesta en «La verdad de la certeza de sí mismo». Al respecto, Hegel sostiene:

$[\mathrm{P}]$ ara ella [sc. para la autoconciencia], hay el ser-otro en cuanto un ser, o en cuanto momento diferenciado; pero también hay para ella la unidad

\footnotetext{
${ }^{1}$ Las referencias de la $F E$ se realizan por la numeración canónica de la traducción castellana de Gómez Ramos (Abada, 2010), que sigue la edición de Wolfgang Bonsiepen y Reinhard Heede (Gesammelte Werke, Band 9, Hamburg, 1980). Para marcar la distinción entre la referencia por páginas y por número de edición canónica usamos «:» y «,» respectivamente. En este trabajo utilizamos el término «subjetividad» en sentido amplio. Entendemos que, así como las figuras de la conciencia exponen diversas "concepciones del objeto", como sostiene Siep (2000: 87, 97), así también ellas y las figuras del mundo desarrollan diversas concepciones del sujeto o de la subjetividad. Por otra parte, no restringimos el erotismo a la Autoconciencia porque, como mostramos en el tercer apartado de este trabajo, la Begierde se extiende más allá del Capítulo IV en el que se expone dicha figura.
} 
de ella misma con esta diferencia, en cuanto segundo momento diferenciado. Con el primer momento, la autoconciencia queda conservada como conciencia, y se conserva para ella toda la extensión del mundo sensible; pero, a la vez, sólo en cuanto está referida a su segundo momento, la unidad de la autoconciencia consigo misma; con lo que esta unidad es para la autoconciencia un subsistir que, sin embargo, sólo es fenómeno, aparición, o diferencia que no tiene ser en sí. Mas esta oposición entre su aparición y su verdad no tiene más esencia suya que esta verdad, a saber: la unidad de la autoconciencia consigo misma; esta unidad tiene que llegar a serle esencial a ella; es decir, la autoconciencia es deseo sin más (Begierde überhaupt). A partir de ahora, la conciencia tiene, en cuanto autoconciencia, un objeto doble: uno, el inmediato, el objeto de la certeza sensorial y del percibir, el cual, sin embargo, está marcado para ella con el carácter de lo negativo, y el segundo, a saber, símisma, que es la esencia verdadera y, de primeras, sólo está presente, por ahora, en la oposición del primer objeto. La autoconciencia se expone aquí como el movimiento por el que esta oposición queda cancelada y asumida, convirtiéndosele en la igualdad de sí misma consigo misma (FE, 104; el subrayado es del original). ${ }^{2}$

El primero de los resultados del desarrollo de la figura de la Conciencia es la emergencia de la autoconciencia (Selbstbewußtsein), que tiene lugar en el Capítulo III a través de la explicación (Erklärung) que el entendimiento (Verstand) realiza del juego de fuerzas. Lo que se releva con la explicación es, precisamente, que la conciencia es la verdad del saber del objeto (FE, 100-101; Bowman, 2008). Sin embargo, el segundo resultado es la persistencia de la contraposición entre la conciencia y su objeto. La verdadera unidad de éstos no se logra en el Capítulo III porque el entendimiento carece de reflexividad y tiene un posicionamiento teórico, externo y abstracto respecto de su objeto.

Lo peculiar del escenario fenomenológico inicial del Capítulo IV es, entonces, la persistencia de la contraposición entre la conciencia y su objeto, el mundo sensible y perceptible. La autoconciencia es justamente la superación de dicha contraposición, superación mediante la cual aquella alcanza la unidad consigo misma.

\footnotetext{
${ }^{2}$ Para evitar posibles confusiones del lector, el texto alemán incorporado en las citas respetará la letra cursiva del texto original.
} 
Pero a diferencia del posicionamiento teórico de la Conciencia, «La verdad de la certeza sí mismo» expone una forma o concepción práctica de la subjetividad (Pinkard, 1994: 43-53; Siep 2000: 97-100). Según Pippin, la Begierde inicia este "giro práctico» en la experiencia de la conciencia (2001: 20-32). Ya no se trata de la facultad sensorial, de la percepción, del entendimiento ni de la explicación del objeto, sino de un «hacer» por el que la unidad de la autoconciencia con el mundo y consigo misma se realice como logro (erreichen - achievement) práctico, esto es, como el resultado de su propia actividad.

La Begierde tiene una función esencial en la realización de la autoconciencia. Como señala Förster (2008: 42), se trata de un concepto epistemológico, no psicológico. La Begierde es una modalidad de conocimiento y autoconstitución, no una cualidad o aspecto psíquico. En términos generales, aquella constituye el posicionamiento práctico y negativo de la autoconciencia, por medio del cual ésta busca superar la contraposición con su objeto y realizar la unidad consigo misma. ${ }^{3}$ En términos más específicos, y como desarrollamos a continuación, la Begierde es la aniquilación (vernichten) del objeto independiente, mediante la cual la autoconciencia alcanzaría la verdad de la certeza de sí como ser autónomo.

Allende esta caracterización general, cabe destacar que el término «Begierde» es sumamente complejo y ha recibido distintas traducciones e interpretaciones. En español contamos con dos traducciones clásicas. Por un lado, la de Roces, quien traduce "Begierde» por «apetencia» (FCE, 2007: 108). Por otro lado, la más reciente de Gómez Ramos, que lo hace por «deseo» (Abada, 2010: 247). Estas dos traducciones reflejan, en cierto sentido, el debate que la Hegelforschung plantea acerca de la extensión de la concepción erótica de la autoconciencia en la $F E$, discusión que se limita fundamentalmente al Capítulo IV y, en especial, a su parte introductoria y a su Sección A.

Según una primera línea interpretativa, la Begierde no alcanza a la totalidad del movimiento de la Autoconciencia. Como «apetito animal» y aniquilación del objeto independiente, se restringe al primer movimiento de esta figura, expuesto en la parte introductoria de "La verdad de la certeza de sí mismo" (Brandom, 2007: 132-135; Findlay, 1958: 96; Siep, 2000: 100-101; Neuhouser, 1986). Una segunda línea interpretativa comprende que la concepción erótica

3 En este sentido estamos en desacuerdo con McDowell (2007: 38), para quien la Begierde es una mera paráfrasis (paraphrase) de la referencia negativa de la autoconciencia respecto de su objeto. 
de la subjetividad se extiende a la Sección A del Capítulo IV, «Autonomía y no autonomía de la autoconciencia; dominación y servidumbre» ${ }^{4}$ (Jenkins, 2009; McDowell, 2007: 38-41; Pinkard, 1994: 46 y ss.; Pippin, 2011: 55 y ss; Rendón, 2012). Por otra parte, para autores un poco más radicales, entre los que se destaca Butler (1987: 1-60), el deseo llega a caracterizar a la noción hegeliana de la subjetividad en general, al menos en lo que respecta a la desarrollada en $F E$. Paradójicamente, Butler no toma en consideración la totalidad de la obra, sino que limita su abordaje principalmente al Capítulo IV y hace sólo algunas breves alusiones a los capítulos anteriores.

Las tesis que intentamos mostrar en este trabajo son dos. La primera es que la concepción erótica de la subjetividad en la $F E$ tiene un sentido muy restringido: es la negación meramente inmediata del objeto independiente, la aniquilación del objeto vivo que no alcanza la completa negación del ser-otro porque la dimensión erótica de la subjetividad requiere e implica la autonomía del objeto en cuestión. La segunda tesis es que, en cuanto posicionamiento práctico y negativo de la autoconciencia respecto de su objeto, la concepción erótica de la subjetividad no se limita al Capítulo IV, aunque es en este último, y específicamente en su parte introductoria, donde se establecen los caracteres esenciales de dicha concepción. En los dos apartados que siguen exponemos respectivamente las tesis mencionadas.

\section{Demarcación del sentido propio de la Begierde}

\subsection{La Begierde en la parte introductoria del Capítulo IV}

Como indicamos en la Introducción, la Begierde entra en escena en la parte introductoria de "La verdad de la certeza de sí mismo». Allí, Hegel especifica que el primer objeto de la autoconciencia erótica es la Vida (Leben) o infinitud (Unendlichkeit) reflexionada dentro de sí (FE, 104-105). La infinitud, recordemos, es el último objeto del Entendimiento (Capítulo III). Sin embargo, no se trata ahora del "concepto» de la infinitud. En las primeras líneas del Capítulo IV, el filósofo sostiene que, con la figura de la Autoconciencia, el concepto (Begriff) del objeto se supera ante el «objeto efectivamente real (wirklicher Gegenstand)»

\footnotetext{
4 De aquí en adelante, «Autonomía y no autonomía de la autoconciencia».
} 
$(F E, 103)$. En este sentido, la Vida como infinitud reflexionada dentro de sí no es ya el concepto de infinitud sino la «substancia simple y fluida (einfache flüssige Substanz)» (FE, 104-105; Beiser, 2005: 180-181).

Hegel distingue dos movimientos que conforman la unidad de la Vida como tal. El primero es el escindirse ella misma en miembros (Glieder) o partes (Teile) para sí, es decir, en figuras autónomas (selbständige Gestalten) que, en tanto que tales, tienen su propio subsistir (Bestehen). Son las «figuras vitales» en las que la Vida se escinde internamente, o sea, figuras del medio vital universal. El segundo movimiento es la superación de las diferencias subsistentes $(F E, 105)$. Se trata, en este caso, de la Vida como medio universal o substancia fluida que cancela sus miembros diferenciados en y por su propio movimiento. En este sentido, en su conjunto y unidad, la Vida es el movimiento infinito de configuración y superación de sus propias figuras (Neuhouser, 2007: 41).

Ahora bien, la autoconciencia, especifica Hegel, es una (i) «figura autónoma» $\mathrm{y}$ «subsistente» que es (ii) «para sí» y (iii) «para la cual es la unidad infinita de las diferencias» (FE, 105-106; el subrayado es del original). Según la primera de las caracterizaciones (i), la autoconciencia es un miembro o figura vital, en el sentido explicitado en el párrafo anterior. Pero a diferencia de los otros miembros en los que la Vida se escinde, (ii) la autoconciencia se sabe a sí misma como universalidad simple o género (Gattung), es decir, como una figura vital autónoma que está relacionada con otras figuras vitales y que, como éstas, se disuelve o desaparece en el medio universal. ${ }^{5}$ Finalmente, la tercera de las caracterizaciones (iii) señala que esta figura vital para-sí, la autoconciencia, tiene por objeto la Vida en tanto que movimiento de superación y unidad de sus propias diferencias.

La contraposición entre la Vida y la autoconciencia es el marco general en el que toma lugar la acción propia de la Begierde, la cual consiste en el acto de aniquilar (vernichten) el objeto a través del consumo (Aufzehren), a fin de superar la contraposición indicada y probar la autonomía (Selbständigkeit) de la autoconciencia. Al respecto, Hegel sostiene:

\footnotetext{
5 Butler (2010: 71-73) propone entender «Gattung» como sinónimo de «especie humana». En este sentido, la autoconciencia sería la figura vital con conciencia de sí en tanto que tal, idea que también sostiene Neuhouser (2007: 41). Honneth (2010: 23-29) parece sugerir algo similar, aunque para él la conciencia de sí cual "género humano» es el resultado del movimiento del deseo y aquello que genera la búsqueda de reciprocidad mediante el reconocimiento.
} 
En el primer momento está la figura subsistente [sc. la autoconciencia]; en cuanto que-es-para-si [...] entra en escena frente a la substancia universal [sc. la Vida], niega esta fluidez y continuidad con ella y afirma de sí que no está disuelta en esto universal, sino que, más bien, se mantiene por particularizarse y separarse de esta naturaleza inorgánica suya, y consumirla ( $F E$, 106; el subrayado es del original).

La autoconciencia, empero, no puede aniquilar directamente la Vida en general, puesto que se trata de un medio universal infinito. Se limita, entonces, a consumir algo viviente (Leben als Lebendiges), es decir, cosas naturales u objetos vivos particulares e independientes $(F E, 106)$.

Parte de la Hegelforschung comprende que aquí se presenta una perspectiva naturalista del deseo y de la autoconciencia (Honneth, 2010: 17-23; Jenkins, 2009: 109, 121; Pinkard, 1994: 48-50; Rendón, 2012: 5-6). ${ }^{6}$ Según esta línea de lectura, la satisfacción de las necesidades básicas y animales (por ejemplo, la necesidad de alimento) es aquello que permitiría a la autoconciencia erótica conservarse como ser natural (animal) e independiente frente a la Vida en la que se disuelve como figura autónoma. Si bien coincidimos con esta interpretación, entendemos que el énfasis de Hegel no está puesto tanto en la acepción digestiva del "consumo», sino más bien en el tipo de negación objetual que la Begierde realiza y en los resultados que deja en la experiencia de la conciencia.

La Begierde es la forma más básica e inmediata de la referencia negativa y práctica que la autoconciencia establece respecto de su objeto a fin de probar la verdad de sí como ser autónomo. Mediante la aniquilación y el consumo, la autoconciencia hace desaparecer los objetos naturales y los convierte en una nulidad (Nichtigkeit) $(F E, 106)$. Esta desaparición trae consigo la cancelación de la oposición entre la autoconciencia y su objeto, y la autoconciencia pone la nulidad de éste como su verdad. En efecto, por la negación inmediata de la Begierde, el objeto se revela para la autoconciencia como aquello que carece de independencia,

\footnotetext{
${ }^{6}$ Brandom (2007: 132-134) sostiene la misma idea, pero desde una lectura pragmatista. Según el autor, el deseo conforma la estructura vital de los seres biológicos, la cual conlleva una clasificación práctica de los objetos. Así, por ejemplo, el hambre (deseo) genera un acto determinado, comer (acción), lo cual implica la consideración de ciertos objetos como alimentos (clasificación pragmática de los objetos).
} 
pues ella se sabe como el principio negativo que lo hace desaparecer. ${ }^{7}$ De esta manera, la Begierde, por un lado, confirma a la autoconciencia la certeza de la nulidad del objeto autónomo y, por otro lado, deja como resultado el logro de la certeza verdadera de la autoconciencia o, en otros términos, el sentimiento de su unidad consigo misma. Al respecto, Hegel sostiene:

[L]o consumido es la esencia; precisamente con ello, la individualidad, que se mantiene al precio de lo universal y se otorga el sentimiento de su unidad consigo misma (Gefühl ihrer Einheit mit sich selbst), cancela su oposición a lo otro, por medio de la cual ella es para sí [...] La autoconciencia sólo está cierta de sí misma cancelando y asumiendo a ese otro que se le presenta como vida autónoma: es deseo (das Selbstbewußtsein hiermit seiner selbst nur gewiß durch das Aufheben dieses Anderen, das sich ihm als selbständiges Leben darstellt; es ist Begierde). Cierta como está de la nulidad (Nichtigkeit) de esto otro, lo pone para sí como su verdad, aniquila al objeto autónomo (vernichtet den selbständigen Gegenstand) y se otorga así la certeza de sí misma como certeza verdadera (wahre Gewißheit), como una certeza tal que ha llegado a ser de modo objetual (gegenständliche Weise) a los ojos de ella misma (FE, 106-107; el subrayado es del original).

La acción erótica, sin embargo, se revela insuficiente para el proyecto de autonomía de la autoconciencia. La Begierde realiza una aniquilación inmediata del objeto que no logra su completa negación porque, lejos de negarlo en su totalidad, vuelve a engendrarlo de nuevo. Para la Begierde es necesario que se mantenga el objeto independiente y subsistente. Por lo tanto, el erotismo de la autoconciencia no hace sino contradecir sus pretensiones iniciales, multiplicando la esfera de objetos autónomos a aniquilar en un movimiento indefinido (Neuhouser, 1986: 252-253). Por esta razón, también el erotismo de la autoconciencia se conserva en esta modalidad negativa. A propósito de esto, Hegel sostiene:

\footnotetext{
7 En este sentido, Siep (2000: 100) sostiene que la Begierde es la forma más elemental de la demostración del mero ser-para-sí de la autoconciencia. Pippin (2011: 28-31) entiende algo similar al afirmar que el deseo es el modo más básico de la naturaleza aperceptiva de la conciencia práctica que se sabe a sí como ser vivo.
} 
[C] ancelar la subsistencia individual es, en la misma medida, generar (Erzeugen) dicha subsistencia [...] En esta satisfacción (Befriedigung), [la autoconciencia] hace la experiencia de que su objeto es autónomo (die Erfahrung von der Selbständigkeit seines Gegenstandes), se sostiene por sî mismo. El deseo y la certeza de sí misma que ha alcanzado en su satisfacción están condicionados (bedingt) por el objeto, pues ella, esa certeza, es cancelando a eso otro (Aufheben dieses Anderen); para que tal cancelación tenga lugar, tiene que haber ese otro ( $\mathrm{da} ß$ dies Aufheben sei, muß dies Andere sein). La autoconciencia no puede cancelarlo, entonces, por una referencia negativa (negative Beziehung) por parte de ella; por eso, antes bien, vuelve a engendrarlo de nuevo, como al deseo (es erzeugt ihn darum vielmehr wieder, so wie die Begierde). De hecho, la esencia del deseo es algo distinto que la autoconciencia (Es ist in der Tat ein Anderes als das Selbstbewußtsein, das Wesen der Begierde); y es por medio de esta experiencia como le ha devenido a ella esta verdad (FE, 106-108).

Tras el fracaso de la Begierde, la referencia práctico-negativa de la autoconciencia respecto de su objeto prosigue con el goce (Genuß) y el trabajo (Arbeit), de los cuales nos ocupamos a continuación.

\subsection{El goce y el trabajo en la Sección A del Capítulo IV}

El goce y el trabajo se exponen en la Sección A del Capítulo IV, «Autonomía y no autonomía de la autoconciencia». El contexto general de este momento fenomenológico es la duplicación (Verdopplung) de la autoconciencia. El objeto de esta última ya no es el "algo vivo», la cosa natural, sino otra autoconciencia (anderes Selbstbewußtsein). A diferencia del objeto del deseo, que es sólo autónomo y no se puede aniquilar, el nuevo objeto es «tanto yo como objeto» $(F E, 108$; el subrayado es del original). Esto quiere decir que el nuevo objeto es, al igual que la primera autoconciencia, un objeto autónomo para-sí y un principio de negación absoluta, es decir, un objeto que lleva «a cabo él mismo la negación en él» y que «en sí mismo, pone su ser otro, o la diferencia, como un objeto nulo y es autónomo al hacerlo» $(F E, 108)$. Es precisamente en este nuevo objeto en el que la autoconciencia debe hallar su satisfacción (Befriedigung), de manera tal de realizar la unidad consigo misma en su unidad con el ser-otro. 
El concepto de la unidad de la duplicación es lo que Hegel llama «reconocimiento» (Anerkennung): la unidad de la autoconciencia consigo misma en su ser otro, la realización del ser-para-sí de ambas autoconciencias mediadas recíprocamente $(F E, 108-110)$. Con el reconocimiento recíproco aparece ya el concepto de espíritu (Geist), sustancia absoluta y unidad espiritual en la que las autoconciencias opuestas alcanzan su libertad y autonomía perfectas, el «yo que es nosotros, y nosotros que es yo» (FE, 108; el subrayado es del original).

Para una parte de la Hegelforschung, como indicamos en la introducción de este trabajo, la Begierde se extiende a «Autonomía y no autonomía de la autoconciencia» y está presente en la conocida dialéctica de la dominación (Herrschaft) y la servidumbre (Knechtschaft). ${ }^{8}$ Si bien cada uno de los autores tiene un lineamiento hermenéutico propio, la tesis general que comparten es que la parte introductoria del Capítulo IV desarrolla el comportamiento natural de la autoconciencia, expresado en el deseo natural, mientras que la Sección A expone la actitud reflexionada de la autoconciencia a partir del deseo humano, que es precisamente el deseo de reconocimiento. ${ }^{9}$ En este sentido, la autoconciencia dejaría de ser presa de sus deseos e impulsos naturales y comenzaría a afirmar su autonomía espiritual mediante el reconocimiento intersubjetivo.

En contraposición a este lineamiento, nosotros consideramos que la Begierde no está presente como tal en «Autonomía y no autonomía de la autoconciencia». Con esto no queremos decir que no pueda observarse cierta espiritualización del deseo en la Sección en mencionada, sino que la Begierde tiene rasgos específicos y, por lo tanto, no puede confundirse ni ser extendida a otros movimientos de la autoconciencia. En «Autonomía y no autonomía de la autoconciencia» se exponen dos formas del referir negativo de la autoconciencia respecto de su objeto: el goce y el trabajo. Ambos están vinculados directamente con la Begierde pero no se identifican con ella.

El goce y el trabajo se desarrollan en el marco de la dialéctica del señor (Herr) y el siervo (Knecht), momento inmediatamente posterior a la lucha a vida o muerte $(F E, 111-112) .{ }^{10}$ Tras los resultados frustrados del combate, se ponen

8 Butler (1987: 43-45), Jenkins (2009: 105-107, 130), McDowell (2007: 48), Pinkard (1994: 51-57), Pippin (2011: 32, 36-37), Rendón (2012: 2, 10 y ss.).

9 Cabe aclarar que el término "deseo de reconocimiento» no es de Hegel, sino una expresión acuñada por Kojève ([1947] 2006: 13) y de la cual la Hegelforschung se ha hecho eco.

10 No reconstruimos todos los momentos de la dominación y la servidumbre porque, dado nuestro objeto de investigación, nuestro interés se centra solamente en la Begierde y su 
dos figuras contrapuestas de la conciencia, cuya reconciliación, a partir del reconocimiento recíproco, lograría la unidad de la autoconciencia consigo misma. Una de tales figuras es el señor, la conciencia autónoma (selbständiges Bewußtsein) que es para-sí. La otra es el siervo, la conciencia no autónoma (unselbständiges Bewußtsein), conciencia que no es puramente para sí, sino para otro. Esta última es aquella que no arriesgó su vida en la lucha y no pudo probar su independencia respecto de la determinidad vital de la existencia. Por esta razón, a la conciencia servil le es esencial la coseidad (Dingheit).

El señor es la conciencia mediada (vermittelt) consigo misma a través de la conciencia no autónoma. Esta mediación se establece en un doble sentido. Por un lado, el señor se refiere mediatamente a la cosa, objeto de la Begierde, a través del siervo. Por otro lado, se refiere mediatamente al siervo a través de la cosa. $\mathrm{Al}$ respecto, Hegel sostiene:

Al señor, en cambio, por esta mediación le adviene la referencia inmediata (unmittelbare Beziehung) en cuanto negación pura (reine Negation) de la cosa, o dicho en otros términos, el disfrute (Genuß). Lo que el deseo (Begierde) no lograra, lo logra él: acabar y satisfacerse en el goce (damit fertig zu werden und im Genusse sich zu befriedigen). El deseo no lo lograba a causa de la autonomía de la cosa; pero el señor que ha intercalado al siervo entre la cosa y él, se concatena, gracias a esto, con la no autonomía de la cosa, y puramente la disfruta; el lado de la autonomía se lo deja al siervo, que la trabaja (bearbeitet) [...] En el momento que corresponde al deseo (Begierde) en la conciencia del señor, parecía, ciertamente, que a la conciencia que sirve le toca en suerte el lado de la referencia inesencial hacia la cosa, en tanto que la cosa contiene allí su autonomía. El deseo (Begierde) se ha reservado el puro negar del objeto, y así, el sentimiento de sí mismo (Selbstgefühl) sin mezcla. Pero esta satisfacción (Befriedigung) es, por eso mismo, sólo un desaparecer (ein Verschwinden), pues le falta el lado objetual (gegenständliche Seite) o la persistencia (das Bestehen). El trabajo (Arbeit), el cambio, es deseo

supuesta extensión en la Sección A del Capítulo IV. Por otro lado, la Hegelforschung no señala la lucha a vida o muerte como parte de la «dialéctica del deseo». La excepción es Butler, para quien la lucha en cuestión representa una erótica anticorporal (anti-corporeal erotic), en la que cada autoconciencia busca aniquilar el cuerpo de la otra (1987: 43-60). No nos detenemos en esta lectura (i) porque supone el desarrollo de su interpretación de las conciencias enfrentadas como cuerpos vivos y (ii) porque no es un locus clásico de debate dentro de la Hegelforschung. 
inhibido (gehemmte Begierde), retiene ese desaparecer (aufgehaltenes Verschwinden), o dicho en otros términos, el trabajo forma y cultiva (bildet). La referencia negativa al objeto se convierte en la forma (Form) de éste, y en algo que permanece (Bleibenden); porque precisamente es a los ojos del que trabaja que el objeto tiene autonomía ( $F E, 113-115$; el subrayado es del original).

El goce es la referencia negativa que el señor mantiene con el objeto, en particular, con las cosas trabajadas por el siervo. En términos más específicos, el disfrute es la negación pura de cosa y la referencia inmediata a ésta. Podemos establecer tres diferencias entre el goce y la Begierde.

La primera de ellas respecta al carácter inmediato. Como dijimos en 2.1., la Begierde también se caracteriza por su inmediatez. Sin embargo, según entendemos, no se trata del mismo carácter inmediato. A diferencia de la referencia inmediata que se establecía entre la autoconciencia y el algo viviente, la relación entre el señor y la cosa está mediada por el siervo. En este sentido, comprendemos que el goce implica una inmediatez mediada y no se identifica con la referencia pura o meramente inmediata de la Begierde.

La segunda diferencia respecta al objeto propio de la referencia indicada. A diferencia de la Begierde, cuyo objeto era el algo viviente o la cosa natural, el goce tiene como objeto la cosa trabajada por el siervo. El objeto con el que logra acabar el disfrute del seńor no es la cosa en su naturalidad, sino un «producto humano», una cosa espiritual.

La tercera de las diferencias consiste en el resultado positivo del goce. La Begierde, como expusimos en 2.1., es un movimiento paradójico y frustrado de la autoconciencia. En lugar de realizar la completa negación de su objeto, vuelve a engendrarlo de nuevo, puesto que la cosa natural mantiene su autonomía. En contraposición, el disfrute, en tanto que negación pura de la cosa, logra la completa negación del objeto porque para el señor la cosa carece de autonomía. Por esta misma razón, la negación del objeto alcanzada en el goce no implica la pérdida del carácter soberano del señor sobre el mundo natural, ya que el lado de la autonomía del objeto le corresponde al siervo (Neuhouser, 2007: 41).

Sin embargo, el goce es también deficiente. Su insuficiencia radica en que establece sólo una referencia puramente negativa con el objeto: lo hace desaparecer y no afirma su persistencia. A quien compete establecer la persistencia del objeto es a la conciencia trabajadora. 
El trabajo, dice Hegel, es deseo inhibido (gehemmte Begierde). Lo que se inhibe es precisamente el aspecto meramente negativo y destructor de la Begierde, que se mantiene también en el goce. El trabajo es una modalidad de la negación que, a diferencia de la Begierde, no aniquila el objeto ni lo hace desaparecer. Lo que se niega mediante el trabajo es la mera naturalidad (Naturwüchsigkeit) de la cosa. Pero esta actividad es, a la vez, formativa, pues mediante ella la conciencia trabajadora se objetiva en su objeto y éste toma la forma de la subjetividad, convirtiéndose, de esta manera, en un «producto humano». En este sentido, el trabajo logra lo que no lograba ni la Begierde ni el goce: retener el desaparecer de la cosa natural al convertirla en un «objeto espiritual» que tiene la forma permanente de la conciencia que lo forma.

Estas consideraciones muestran que la concepción erótica de la subjetividad tiene un sentido restringido. Si bien el erotismo de la autoconciencia se complejiza a lo largo de la parte introductoria y de la Sección A del Capítulo IV, lo propio de la concepción erótica es su mera inmediatez, desarrollada en la parte introductoria de "La verdad de la certeza de sí mismo». En términos más específicos, podemos decir que la concepción erótica de la subjetividad es: (a) la referencia práctica, negativa y puramente inmediata de la autoconciencia respecto de su objeto; particularmente, la aniquilación y el consumo de la cosa natural e independiente; $(b)$ la acción negativa siempre frustrada debido a la necesidad intrínseca de la persistencia del objeto independiente que requiere e implica la Begierde.

\section{La Begierde más allá de la Sección A del Capítulo IV}

El sentido restringido de la noción de Begierde que acabamos de señalar no implica que la concepción erótica de la subjetividad se limite a la parte introductoria y a la Sección A del Capítulo IV. El término «Begierde» está presente en otras secciones y capítulos de la $F E$.

En la mayoría de las ocasiones, las apariciones de «Begierde» retoman las ideas expuestas en la introducción de "La verdad de la certeza de sí mismo» y en "Autonomía y no autonomía de la autoconciencia». Este es el caso de sus apariciones en «Libertad de la autoconciencia; el escepticismo, el estoicismo y la conciencia desdichada", Sección B del Capítulo IV. Aquí, la primera aparición de «Begierde» vuelve sobre la idea de que la expansión de la vida y su movimiento 
constituyen el objeto contra los que actúan el deseo y el trabajo $(F E, 117)$. En segundo lugar, se repite que el deseo y el trabajo son una "orientación negativa hacia el ser-otro» que no logra la completa negación del objeto y que, por esta razón, se diferencia de la actividad del escepticismo $(F E, 119) .{ }^{11}$ En tercer lugar, se retoma la referencia negativa hacia el objeto del deseo y del trabajo para compararla con la relación que se establece entre la conciencia inesencial y el más allá configurado. El segundo momento de esta relación consiste en que la conciencia inesencial, en cuanto que esencia individual, se comporta como lo hacen el deseo y el trabajo respecto de la realidad efectiva, es decir, de manera negativa $(F E, 124)$. La aparición más relevante en esta sección es la cuarta, que establece el vínculo entre la Begierde y la conciencia desventurada. Mediante el deseo y el trabajo -sostiene Hegel- la conciencia alcanza la certeza interior de sí misma gracias a la superación de la autonomía del objeto que aquellas actividades, cada una a su manera, realizan. En este nuevo contexto, el sentimiento de sí se equipara al ánimo puro (reines Gemüt). Por su parte, la conciencia desventurada «sólo se encuentra como deseante y como trabajando (das unglückliche Bewußtsein aber findet sich nur als begehrend und arbeitend)» (FE, 126). ${ }^{12}$ Pero a diferencia de la mera conciencia erótica y trabajadora, y del ánimo puro, la conciencia desdichada no tiene la certeza y el sentimiento de sí para sí misma. Para sí, ella es «la certeza rota (gebrochene Gewißsheit) de sí misma» y «la verificación que ha obtenido por medio del deseo y el trabajo está, por ende, igualmente rota» ( $F E, 127$; el subrayado es del original). Finalmente, en quinto lugar, «Begierde» aparece en el marco de la conciencia individual que da gracias y al hacerlo alcanza la satisfacción efectiva del sentimiento de sí. Aquí el término en cuestión sólo se menciona para indicar que parte de este logro radica en que la conciencia ha sido Begierde (FE, 128).

En el resto de la $F E$, el término «Begierde» vuelve a aparecer en varias ocasiones, pero con otros sentidos y no como el posicionamiento práctico y negativo

\footnotetext{
11 «Es evidente que, así como el estoicismo corresponde al concepto de conciencia autónoma que aparecía como relación de señorío y servidumbre, el escepticismo corresponde a la realización (Realisierung) de dicha relación en cuanto orientación negativa hacia el ser-otro (als der negativen Richtung auf das Anderssein), en cuanto deseo y trabajo. Pero si el deseo y el trabajo no podían ejecutar la negación para la autoconciencia, en cambio, esta orientación polémica hacia la autonomía plural de las cosas sí tendrá éxito, porque se vuelve contra ellas en cuanto autoconciencia libre previamente acabada dentro de sí; dicho de modo más determinado, porque tiene en ella misma el pensar o la infinitud, y de ese modo, a sus ojos, esas cosas autónomas conforme a sus diferencias, sólo son en cuanto magnitudes evanescentes» ( $F E$, 119; el subrayado es del original)

12 El subrayado es del original, salvo los subrayados de «como».
} 
de la autoconciencia respecto de su objeto. En la única sección en que esto sí ocurre es en "La realización efectiva de la autoconciencia racional por medio de sí misma» del Capítulo V, más específicamente en "El placer y la necesidad». Se trata aquí de la conciencia que se arroja a la vida como individualidad pura. Su actividad -dice Hegel- es la actividad del deseo, pero sólo según un momento de este: la aniquilación (Vertilgung) de la autonomía del objeto en tanto que su mismidad (Selbstheit). Pero a diferencia de la parte introductoria del Capítulo IV, en este nuevo contexto la separación entre la conciencia y su objeto está mediada por la representación. Por esta razón, de la aniquilación resulta ahora una concepción representativa de la autonomía. En palabras del filósofo:

Su actividad (Tun) es actividad del deseo (Begierde) sólo según un momento; no busca la aniquilación (Vertilgung) de toda la esencia del objeto, sino sólo la forma de su ser-otro o de su autonomía, que es una apariencia sin esencia; pues, en sí, a ese ser-otro lo considera como la misma esencia, o como su mismidad (seine Selbstheit). El elemento en que el deseo y su objeto persisten como autónomos y recíprocamente indiferentes es la existencia viva (das lebendige Dasein); el disfrute del deseo (der Genuß der Begierde) cancela ésta en la medida en que ella corresponda al objeto del deseo. Mas, aquí, este elemento, que les da a ambos su realidad efectiva separada, es, más bien, la categoría, un ser que es esencialmente un ser representado (ein vorgestelltes); es, por tanto, la conciencia de la autonomía (das Bewußtsein der Selbständigkeit) ( $F E$, 199; el subrayado es del original).

«Begierde» vuelve a aparecer en «El espíritu», pero no para determinar el posicionamiento de la autoconciencia respecto de su objeto. En «El mundo ético, la ley divina y la ley humana, el hombre y la mujer» aparece, en primer lugar, en referencia a la sustancia ética familiar. En este caso, la Begierde está orientada a las necesidades (Bedürfnisse), a las cuales se refiere la adquisición y conservación de las riquezas y el poder $(F E, 243)$. En segundo lugar, «Begierde» se introduce para caracterizar la eticidad de la mujer y el derecho del deseo por parte del varón (FE, 248-249). En tercer lugar, en «La acción ética, el saber humano y el saber divino, la culpa y el destino», "Begierde» hace referencia al deseo del joven orientado a la femineidad $(F E, 259)$. En cuarto lugar, en "La certeza moral, el alma bella, el mal y el perdón», Hegel sostiene que la acción de la certeza moral aparece meramente como el cumplimiento del placer y de la Begierde cuando 
la conciencia abandona el sí mismo puro del deber $(F E, 352)$. Finalmente, en «La obra de arte viva», en el Capítulo VII, «La religión», Hegel habla de la cosa utilizable como objeto de la Begierde (FE, 386).

Esta reconstrucción de las apariciones de «Begierde» en la $F E$ ponen de relieve que se trata de un concepto importante que está presente en varios momentos del recorrido fenomenológico de la conciencia natural hacia el saber real. En cada uno de ellos, el erotismo adquiere su propia «función», según el contexto. En este sentido, entendemos que la concepción erótica de la subjetividad no se restringe ni se limita al Capítulo IV.

\section{Conclusión}

Recapitulando lo dicho y para concluir, podemos decir que la concepción erótica es una de las formas más básicas que la subjetividad adquiere en el camino de la conciencia natural hacia el saber absoluto. Se trata esencialmente de una concepción práctica de la subjetividad que radica en la referencia negativa y meramente inmediata (unmittelbare Beziehung) del objeto independiente. Esta negación tiene una modalidad específica: es el acto de aniquilar (vernichten) y consumir (aufzehren). Por su parte, el objeto también tiene un carácter peculiar en la concepción erótica del sujeto: consiste en el algo viviente (Leben als Lebendiges) o la cosa viva-natural. Estas características distinguen la Begierde del goce (Genuß), aniquilación inmediata-mediata del producto humano, y del trabajo (Arbeit), negación espiritual de la naturalidad de la cosa que aquel forma y cultiva.

Pero otro elemento no menos importante de esta concepción es aquello que logra la acción erótica y que consiste en el sentimiento (Gefübl) de la unidad de la autoconciencia consigo misma. Se trata de un logro primario y básico de la autoconciencia que se restringe a la certeza verdadera (wahre Gewißheit), esto es, a la certeza inmediata de sí misma que llega ser de manera objetual por la desaparición objetiva y efectiva del objeto. Este punto es importe no sólo en lo que respecta a la reconfiguración posterior del sentimiento de sí como el ánimo puro de la conciencia inesencial y como la certeza rota de la conciencia desdichada (Capítulo IV, B). Lo que pone de relieve la reaparición de la Begierde en «El placer y la necesidad» (Capítulo V) es también el carácter no representativo de la concepción erótica de la subjetividad. Cuando la representación es aquello que 
establece la separación entre el objeto y la conciencia, el logro que se obtiene por la superación de tal escisión representativa es la conciencia de la autonomía, más no el sentimiento de tal independencia, que es lo propio del erotismo subjetivo.

En este sentido, si bien la Begierde no se restringe a la introducción y a la Sección A del Capítulo IV, lo propio de la concepción erótica de la subjetividad es aquello que se desarrolla en la parte introductoria de «La verdad de la certeza de sí mismo", donde se establecen las características esenciales que la componen y que son aquellas que se retoman en las restantes apariciones de «Begierde» a lo largo de la obra al momento de hacer referencia al posicionamiento práctico, negativo e inmediato de la conciencia respecto de su objeto.

\section{Bibliografía}

Beiser, F. (2005). Hegel. New York/London: Routledge.

Bowman, B. (2008). «Kraft und Verstand. Hegels Übergang zum Selbstbewusstsein in der Phänomenologie des Geistes». Hegels Phänomenologie des Geistes. Ein kooperativer Kommentar zu einem Schlüsselwerk der Moderne. Eds. K. Vieweg \& W. Welsch. Frankfurt: Suhrkamp, pp. 153-170.

Brandom, R. (2007). "The Structure of Desire and Recognition: Self-Consciousness and Self-Constitution». Philosophy and Social Criticism Vol. 33, N 1, pp. 127-150.

Butler, J. (2010). «Le corps de Hegel est-il en forme: quelle forme?». Sois mon corps. Une lecture contemporaine de la domination et de la servitude chez Hegel. Eds. J. Butler \& C. Malabou. Montrouge: Bayard Éditions, pp. 55-84.

(1987). Subjects of Desire. Hegelian Reflections in Twentieth-Century France. New York: Columbia University Press.

Findlay, J. (1959). Hegel. A Reexamination. New York: Macmillan.

Förster, E. (2008). «Hegels 'Entdeckungsreisen', Entstehung und Aufbau der Phänomenologie des Geistes». Hegels Phänomenologie des Geistes. Ein kooperativer Kommentar zu einem Schlüsselwerk der Moderne. Eds. K. Vieweg \& W. Welsch. FrankfurtM: Suhrkamp, pp. 37-57.

Hegel, G. W. F. (1807). Phänomenologie des Geistes. Publicada por primera vez bajo el título System der Wissenschaft. Erster Theil, Die Phänomenologie des Geistes. Bamberg und Würzburg (Fenomenología del espiritu. Edición bilingüe. Trad. de A. Gómez Ramos. Madrid: Abada, 2010). 
Honneth, A. (2010). «Von der Begierde zur Anerkennung; Hegels Begründung von Selbstbewußtsein». Das Ich im Wir. Studien zur Anerkennungstheorie. Berlin: Suhrkampp, pp. 15-32.

Jenkins, S. (2009). «Hegel's Concept of Desire». Journal of the History of Philosophy Vol. 47, $\mathrm{N}^{\circ} 1$, pp. 109-130.

Kojève, A. (1947). Introduction à la lecture de Hegel. París: Gallimard (La dialéctica del amo y del esclavo en Hegel. Trad. de J. J. Sebreli. Buenos Aires: Leviatán, 2006).

Mcdowell, J. (2007). «The Apperceptive I and the Empirical Self: Towards a Heterodox Reading of "Lordship and Bondage" in Hegel's Phenomenology». Hegel: New Directions. Ed. K. Deligiorgi. Chesham: Acumen, pp. 33-48.

Neuhouser, F. (2009). «Desire, Recognition, and the Relation between Bondsman and Lord». The Blackwell Guide to Hegel's Phenomenology. K. Westphal (Ed.). Oxford: Wiley Blackwell, pp. 37-54.

(1986). «Deducing Desire and Recognition in the Phenomenology of Spirit». Journal of the History of Philosophy Vol. 24 (2), pp. 243-262.

Pinkard, T. (1994). Hegel's Phenomenology: The Sociality of Reason. Cambridge: Cambridge University Press.

Pippin, R. (2011). Hegel on Self-consciousness. Desire and Death in the Phenomenology of Spirit. Princeton-Oxford: Princeton University Press.

Rendón, C. (2012). «La dialéctica del deseo en la Fenomenología del Espíritu de Hegel». Tópicos Vol. 24, pp. 1-16.

SieP, L. (2000). Der Weg der Phänomenologie des Geistes. Ein einführender Kommentar zu Hegels 'Differenzschrift' und 'Phänomenologie des Geistes'. Frankfurt: Suhrkamp.

Recibido: 2/11/2018

Aceptado: 25/12/2018

Este trabajo se encuentra bajo una licencia de Creative Commons ReconocimientoNoComercial-SinObraDerivada 4.0 